\title{
A formação docente no Curso de Licenciatura em Ciências da Natureza: Biologia e Química do IFRS - Campus Porto Alegre: desafios e perspectivas no contexto atual
}

\author{
Cassiano Pamplona Lisboa \\ Instituto Federal do Rio Grande do Sul (IFRS) - Campus Porto Alegre \\ (cassiano.lisboa@poa.ifrs.edu.br)
}

\begin{abstract}
Aline Grunewald Nichele
Instituto Federal do Rio Grande do Sul (IFRS) - Campus Porto Alegre

(aline.nichele@poa.ifrs.edu.br)

Andréia Modrzejewski Zucolotto

Instituto Federal do Rio Grande do Sul (IFRS) - Campus Porto Alegre

(andreia.zucolotto@poa.ifrs.edu.br)

Helen Scorsatto Ortiz

Instituto Federal do Rio Grande do Sul (IFRS) - Campus Porto Alegre

(helen.ortiz@poa.ifrs.edu.br)

Karin Tallini

Instituto Federal do Rio Grande do Sul (IFRS) - Campus Porto Alegre

(karin.tallini@poa.ifrs.edu.br)

Liliane Madruga Prestes

Instituto Federal do Rio Grande do Sul (IFRS) - Campus Porto Alegre

(liliane.prestes@poa.ifrs.edu.br)

Lúcio Olimpio de Carvalho Vieira

Instituto Federal do Rio Grande do Sul (IFRS) - Campus Porto Alegre

(lucio.vieira@poa.ifrs.edu.br)
\end{abstract}

\begin{abstract}
Resumo: Este artigo apresenta uma breve retrospectiva acerca dos processos de criação e reformulação do Curso de Licenciatura em Ciências da Natureza: Biologia e Química, que é ofertado pelo Instituto Federal de Educação, Ciência e Tecnologia do Rio Grande do Sul (IFRS) - Campus Porto Alegre desde o segundo semestre de 2010. O atual Projeto Pedagógico do curso foi reformulado e aprovado no ano de 2016, sendo que a nova versão passou a vigorar em 2017/02. Tal reformulação buscou contemplar demandas específicas elencadas a partir da escuta do Colegiado de Curso, com base nas experiências realizadas até então, e também visando à adequação do Projeto Pedagógico às Diretrizes Nacionais para a Formação Docente, aprovadas pelo Conselho Nacional de Educação e instituídas pela Resolução CNE/CP no 02/2015. Diante disso, o relato apresenta uma síntese de tal processo, que se caracterizou por ampliar o enfoque de componentes curriculares do campo específico da química, assumindo as limitações de integração não alcançadas no projeto original e por demarcar a interlocução entre ensino, pesquisa extensão, articuladas com as redes de ensino.
\end{abstract}

Palavras-chave: Formação Docente; Ensino de Ciências; Projeto Pedagógico.

Teacher training in degree Course in Natural Sciences: Biology and Chemistry IFRS Campus Porto Alegre: challenges and prospects in the current context 
Abstract: This paper presents a brief retrospective about the processes of creation and reformulation of the Degree Course in Natural Sciences: Biology and Chemistry. This course has been offered at the Federal Institute of Education, Science and Technology (IFRS - Campus Porto Alegre) since August 2010. Its current pedagogical Project was reformulated and approved in 2016 and was effective in August 2017. This reformulation sought to address specific demands arising from the dialogue with its collegial body, based on the experiences carried out so far, and also aimed at adapting the pedagogical Project to the National Guidelines for teacher training approved by the National Education Council (Conselho Nacional de Educação - CNE), by the Resolution CNE/CP no. 02/2015. In this context, this paper presents a synthesis of this process. The process was characterized by broadening the curriculum components about Chemistry, assuming the limitations of integration not achieved in the original Project and by demarcating the dialogue among teaching, extension activities and research articulated with the teaching networks.

Keywords: Teacher Training; Science Teaching; Pedagogical Project.

\section{INTRODUÇÃO}

Este artigo apresenta uma breve retrospectiva acerca dos processos de criação e reformulação do Curso de Licenciatura em Ciências da Natureza: Biologia e Química, ofertado pelo Instituto Federal de Educação, Ciência e Tecnologia do Rio Grande do Sul (IFRS) - Campus Porto Alegre, desde o segundo semestre de 2010. $\mathrm{O}$ atual Projeto Pedagógico do curso foi reformulado e aprovado no ano de 2016, sendo que a nova versão passou a vigorar em 2017/02. O referido curso tem como objetivo a formação inicial de educadores para atuarem na Educação Básica, na docência nas áreas de Ciências da Natureza no Ensino Fundamental e Química e Biologia no Ensino Médio.

A oferta deste Curso, em especial, está prevista nas atuais políticas públicas para a formação inicial de professores, face à carência de docentes nas áreas de Ciências, Química e Biologia. Entre tais políticas, citamos a intensificação e a ampliação das ações formadoras com as instituições da Rede Federal de Educação Profissional, Científica e Tecnológica, incluindo a criação dos Institutos Federais de Educação, Ciência e Tecnologia, conforme Lei № 11.892, de 29 de dezembro de 2008. De acordo com a referida Lei, a expansão de cursos nos Institutos Federais deve reservar $20 \%$ (vinte por cento) das vagas para cursos de licenciaturas, prioritariamente para as licenciaturas em Ciências da Natureza e Matemática. Ressaltamos ainda que a oferta do Curso de Licenciatura em Ciências da Natureza: Biologia e Química do IFRS - Campus Porto Alegre foi resultante do mapeamento de demandas relacionadas à formação inicial de docentes para o ensino de Ciências 
para a Educação Básica, em especial, para as áreas de Química e Biologia na região metropolitana.

Em termos de legislação, o artigo 61 da Lei no 9394/96 prevê a ampliação dos espaços de formação inicial e continuada. $O$ atendimento de tal preceito legal está previsto no Plano Nacional de Educação (2014-2024), cuja meta 15 determina a adoção de políticas de formação docente em nível superior para os docentes que atuam na Educação Básica.

A partir do ano de 2017, a oferta dos cursos de licenciatura deve contemplar as atuais Diretrizes Curriculares Nacionais para a Formação Inicial e Continuada dos Profissionais do Magistério da Educação Básica, instituídas pelo Conselho Nacional de Educação, por meio da Resolução CNE/CP nº 02/2015. Diante deste cenário, o Curso de Licenciatura em Ciências da Natureza ofertado pelo IFRS - Campus Porto Alegre, no decorrer do ano de 2016, passou por um processo de reformulação curricular, que contou com a participação de docentes, discentes, técnicos e demais integrantes da comunidade acadêmica. Este processo foi permeado por amplos debates, espaços de estudos, realização de pesquisa qualitativa para a identificação de demandas com a escuta de todos os segmentos, com o resgate da trajetória do curso (incluindo leitura de atas de reuniões pedagógicas, de Colegiado e do Núcleo Docente Estruturante, realizadas em anos anteriores). Além disso, foram utilizados os dados oriundos da última avaliação externa realizada in loco por comissão designada pelo Instituto Nacional de Pesquisas Educacionais (INEP), a qual foi realizada em setembro de 2015, quando o curso foi avaliado com nota 4 (numa escala de 1 a 5 ).

A seguir, apresentamos um breve relato de como tal processo de reformulação curricular foi conduzido e quais os pressupostos que permearam os processos formativos desenvolvidos no decorrer do mesmo.

\section{O processo de reformulação do Projeto Pedagógico do Curso enquanto exercício de escuta e avaliação coletiva}

No que se refere ao processo de reformulação do Projeto Pedagógico do Curso de Licenciatura em Ciências da Natureza, o mesmo foi desencadeado a partir da escuta da comunidade acadêmica, discentes, docentes e técnicos. Tal processo deu-se em ações articuladas entre o Núcleo Docente Estruturante (NDE) e o 
Colegiado de Curso (CC), os quais tiveram reuniões de estudo e debate em torno das necessidades e possibilidades de aprimoramento das ações desenvolvidas desde o ano de 2010. Realizado no ano de 2016, em síntese, constou de reuniões quinzenais dos colegiados e de pesquisas anteriormente realizadas para 0 levantamento de demandas e para adequação às novas Diretrizes Nacionais para a Formação Docente (Resolução CNE/CP no 02/2015). Foram utilizados, ademais, os dados oriundos da última avaliação externa realizada in loco por comissão designada pelo Instituto Nacional de Pesquisas Educacionais (INEP), a qual foi realizada em setembro de 2015, quando o curso foi avaliado com nota 4 (numa escala de 1 a 5$)$.

Conforme citado, a proposta de criação do Curso de Licenciatura em Ciências da Natureza buscou contemplar as demandas apresentadas tanto pela comunidade, quanto pelo Ministério da Educação ao propor a criação dos Institutos Federais. O caráter experimental e inovador é uma das principais características que diferencia nosso curso das demais formações na área. Quanto ao perfil do egresso, cabe destacar que o Curso busca contemplar em sua formação o que vem sendo exigido do professor para o século XXI, conforme referendado no estudo de Mello e Rego (2002), o que inclui o comprometimento com o aprendizado do educando, suas características e dificuldades. Tal entendimento nos remete a refletirmos sobre qual formação propomos no âmbito das licenciaturas, a exemplo do que faz Gadotti quando, ao questionar sobre o que é ser professor hoje, destaca o que segue:

Ser professor hoje é viver intensamente o seu tempo com consciência e sensibilidade. Não se pode imaginar um futuro para a humanidade sem educadores. Os educadores, numa visão emancipadora, não só transformam a informação em conhecimento e em consciência crítica, mas também formam pessoas. Diante dos falsos pregadores da palavra, dos marqueteiros, eles são os verdadeiros "amantes da sabedoria", os filósofos de que nos falava Sócrates. Eles fazem fluir o saber - não o dado, a informação, o puro conhecimento - porque constroem sentido para a vida das pessoas e para a humanidade e buscam, juntos, um mundo mais justo, mais produtivo e mais saudável para todos. Por isso eles são imprescindíveis. (GADOTTI, 2003, p. 17)

Com base no exposto, partimos do entendimento de que o docente deverá ter sólida formação cultural e científica, domínio da língua materna e das tecnologias associadas à sua especialidade. Para isso, o Curso prevê a adoção de estratégias metodológicas que permitam ao egresso o desenvolvimento de capacidades, entre 
as quais citamos: relacionar os conhecimentos científicos com os didáticos e pedagógicos, para melhor gestão dos processos de ensino e aprendizagem; saber trabalhar em equipe para melhor integração curricular e ações interdisciplinares; articular seus saberes com as inovações e com capacidade de gerir seu próprio desenvolvimento profissional. $\mathrm{O}$ atendimento ao exposto implica compreendermos que, como destaca Freire (1996), não há docência sem discência. Requer considerarmos que 0 ato de ensinar exige pesquisar além de envolver 0 comprometimento do educador diante do contexto histórico e social. Portanto, as ações pedagógicas desenvolvidas no decorrer do Curso visam subsidiar o licenciando para que obtenha subsídios teóricos e práticos que promovam a garantia da Educação Básica como direito universal. A escola, por sua vez, é entendida enquanto espaço coletivo de construção identitária dos sujeitos, no qual as diferenças passam a ser valorizadas, o que implica que:

Para tal, todos nós precisaremos passar por um processo de reeducação do olhar. O reconhecimento e a realização dessa mudança do olhar sobre o "outro" e sobre nós mesmos a partir das diferenças deve superar o apelo romântico ao diverso e ao diferente e construir políticas e práticas pedagógicas e curriculares nas quais a diversidade é uma dimensão constitutiva do currículo, do planejamento das ações, das relações estabelecidas na escola. (GOMES, 2007, p. 25)

A partir de tal entendimento e em consonância com a Resolução CNE no 02/2015 (que estabelece as Diretrizes Nacionais para a Formação Inicial e Continuada dos Profissionais do Magistério da Educação Básica) e com as prerrogativas legais acima citadas, o Projeto Pedagógico do Curso de Licenciatura em Ciências da Natureza: Biologia e Química visa:

o reconhecimento e a valorização das diferenças, nas suas diversas dimensões - e especialmente no que se refere à diversidade étnicoracial, sexual, de gênero e identidade de gênero, geracional, cultural e regional, além das diferenças cognitivas e físicas - não se limitam ao respeito e à tolerância nas relações interpessoais, mas, como parte do processo formativo, produz implicações no currículo, na prática pedagógica e na gestão da instituição educativa. (BRASIL, 2015, p. 9)

Nesse sentido, para o exercício docente na Educação Básica, além da apropriação dos conhecimentos específicos, do domínio dos saberes, é 
imprescindível a reflexão em torno dos "fazeres", não como profissionalização precoce, mas como formação básica para o trabalho. Acrescenta-se a isso a necessidade de se construir as competências relacionais do discente, necessárias para a vida corrente. Tais competências dizem respeito ao saber ser e ao saber viver em sociedade, ao aprender a ser como parte do desenvolvimento do humano, conforme indica Dellors (1998).

Dito isso, ao propormos a organização curricular do Curso de Licenciatura em Ciências da Natureza, nos pautamos nos estudos realizados por Moreira (1993), que destaca a relevância da escola no desenvolvimento do espírito crítico, flexibilidade, curiosidade, criatividade, atitude científica e autonomia. Entre os desafios postos à formação docente, o autor destaca o desenvolvimento de habilidades e atitudes, tais como:

O professor precisa tornar-se habilidoso em meios de comunicação que favoreçam a descrição, a interpretação e a renovação de experiências e significados. Precisa, também, familiarizar-se com as características e os métodos da atividade científica hoje. O trabalho na sala de aula precisa abrir-se para uma pluralidade de métodos e de linguagens, visando a favorecer ao aluno a aquisição de processos variados de construção de conhecimento, de comunicação e de expressão. O professor precisa, ainda, capacitarse a atualizar os meios quando novos significados ou as características, os interesses e as necessidades dos alunos assim o exigirem. (MOREIRA, 1993, p. 50)

Logo, o currículo do Curso de Licenciatura em Ciências da Natureza: Biologia e Química busca articular as diferentes áreas de conhecimento, a partir das quais desenvolve ações de ensino, pesquisa e extensão no decorrer do percurso formativo, conforme estruturado nos Núcleos instituídos pela Resolução CNE/CP № $02 / 2015$.

\section{Adequação da estrutura curricular às demandas e ao disposto nas atuais Diretrizes Curriculares Nacionais para a Formação Docente}

De acordo com as Diretrizes Nacionais de Formação Docente, a matriz curricular dos cursos de formação de professores deverá articular os diferentes componentes curriculares e as atividades para enriquecimento curricular por meio dos seguintes núcleos: núcleo de estudos de formação geral, das áreas específicas e interdisciplinares, e do campo educacional, seus fundamentos e metodologias, e 
das diversas realidades educacionais; núcleo de aprofundamento e diversificação de estudos das áreas de atuação profissional, incluindo os conteúdos específicos e pedagógicos; e núcleo de estudos integradores.

No Curso de Licenciatura em Ciências da Natureza: Biologia e Química, os núcleos acima descritos são articulados mediante uma estrutura curricular que se organiza em Unidades de Aprendizagem Pedagógicas (UAP), Unidades de Aprendizagem das Ciências da Natureza (UACN) e Unidades de Aprendizagem Integradoras (UAI). Tais Unidades visam promover a inserção e exploração do ambiente escolar, o seu entorno e a coerência das políticas públicas com as propostas curriculares das instituições de ensino. Buscam ainda consolidar o compromisso de oferecer à sociedade uma variedade de ferramentas e propostas inovadoras de ensino que auxiliem no desenvolvimento do pensamento científico com vistas à superação da desigualdade social e voltadas ao exercício da cidadania.

Em consonância com a Resolução CNE/CP 2/2015, o Curso apresenta carga horária total de 4179 horas, distribuídas em:

I - 446 horas de prática como componente curricular, distribuídas ao longo do processo formativo;

II - 400 horas dedicadas ao estágio supervisionado, nas áreas de Ensino de Ciências para o Ensino Fundamental, Ensino de Química e Ensino de Biologia para o Ensino Médio, e Ensino de Ciências da Natureza para o Ensino Médio;

III - 3133 horas dedicadas às atividades formativas estruturadas pelos núcleos definidos nos incisos I e II do artigo 12 da referida resolução;

IV - 200 horas de atividades teórico práticas de aprofundamentos em áreas específicas de interesse dos estudantes conforme núcleo definido no inciso III do artigo 12 da referida resolução. (INSTITUTO FEDERAL DE EDUCAÇÃO, CIÊNCIA E TECNOLOGIA DO RIO GRANDE DO SUL, 2016, p. 32/33)

A integralização do Curso ocorre após a conclusão de nove etapas, totalizando quatro anos e meio de duração (nove semestres). As etapas, por sua vez, estão articuladas por meio de temas estruturantes que se relacionam com diferentes dimensões do Ensino de Ciências da Natureza, conforme segue: Terra e sua composição (etapas I e II); Terra e suas transformações (etapas III e IV); Vida e sua organização (etapas V e VI); Vida e Evolução (etapa VII) e Vida e Sociedade (etapas VIII e IX). 
Com o intuito de diversificar o percurso formativo do estudante, estão previstas na matriz curricular cinco componentes optativos. A existência dos componentes optativos possibilita ao aluno escolher, semestralmente, dentre um rol previamente estabelecido ${ }^{1}$, quais componentes gostaria de cursar, desde que, obrigatoriamente, realize 220 horas/aula (183 horas) deste tipo de componente curricular. Para o cômputo da carga horária das disciplinas optativas, há ainda a possibilidade de aproveitamento de componentes curriculares cursados na Educação Superior, desde que aprovados pelo colegiado do Curso. Neste caso, somente são validados componentes concluídos após o ingresso na Licenciatura.

Nas atividades de Prática de Ensino como componente curricular, os professores orientam e avaliam o planejamento e desenvolvimento das atividades previstas e buscam promover a socialização das mesmas. No cômputo da carga horária das atividades de Prática de Ensino como componente curricular, consideram-se atividades de planejamento, de observação e de reflexão das mesmas, bem como atividades de registro. A carga horária das práticas de ensino como componente curricular está distribuída ao longo do curso nas Unidades de Aprendizagem Integradoras e Pedagógicas, totalizando 446 horas.

Nos quatro primeiros semestres do curso, privilegiam-se as atividades de prática de ensino como componente curricular sob forma de Projetos Integradores. Os projetos integradores configuram-se em um conjunto de atividades que buscam relacionar as competências desenvolvidas nas três UA's, ao longo de cada etapa, através da argumentação, do planejamento ou da aplicação de uma ação docente, de modo que os conceitos construídos ao longo semestre sejam integrados e contextualizados. Já a partir do sexto semestre do curso, as atividades de Prática de Ensino como Componente Curricular se darão em articulação com os Estágios Supervisionados e com o Trabalho de Conclusão de Curso, como forma de integrar conhecimentos e competências desenvolvidos à prática docente propriamente dita.

O Curso de Licenciatura em Ciências da Natureza: Biologia e Química prevê o desenvolvimento das atividades teórico-práticas de aprofundamentos em áreas específicas de interesse dos estudantes, complementares à Matriz Curricular do curso e necessárias à sua integralização, num total de, no mínimo, 200h. Tais

\footnotetext{
${ }^{1}$ Na versão atual do PPC constam 18 componentes curriculares diferentes. 0 documento completo poderá ser consultado através do link: http://www.poa.ifrs.edu.br/wp-content/uploads/2017/01/ppc-cienciasda-natureza-vigencia2017-2.pdf
} 
atividades relacionadas ao ensino incluem monitorias nos cursos superiores ou da educação básica; atuação no programa de Laboratório de Apoio Didático; participação voluntária em atividades de ensino em área afim ao curso; atuação no Programa Institucional de Bolsa de Iniciação à Docência - PIBID; ações e projetos que são frutos do Programa de apoio a laboratórios interdisciplinares de formação de educadores - LIFE; Programa de Consolidação das Licenciaturas - Prodocência; Programa de Educação Tutorial - PET; atuação em projetos de ensino do Programa Institucional de Bolsas de Ensino do IFRS - PIBEN; ou de outros Programas de Ensino desenvolvidos na Instituição. Podem também abranger componentes extracurriculares da área de ciências, biologia ou química em Instituições de Ensino, ou estágio extracurricular (não obrigatório).

A atual organização curricular do Curso busca proporcionar aos estudantes a inserção no contexto escolar desde os primeiros semestres, tal proposta visa fornecer subsídios para que o licenciando possa aprofundar seus conhecimentos e, ao mesmo tempo, repensar, refletir, transformar e/ou aprimorar as práticas em contextos educativos diversos. Com isso, buscamos que os licenciandos compreendam a importância de conhecer o contexto histórico e social no qual a docência será desenvolvida. Isso remete compreender que:

Conhecer significa uma aventura da qual participam alunos e professores. $\mathrm{Na}$ aventura, conflitos e embates inevitavelmente ocorrem. Na aventura, o compromisso com a construção de uma sociedade mais justa e mais democrática pode desenvolver-se e consolidar-se. Conhecer melhor o mundo pode tornar-se, então, o empenho por transformá-lo. (MOREIRA, 1993, p. 51)

Neste processo de conhecimento, a pesquisa é algo inerente e, portanto, presente em todos os momentos. Desde as investigações realizadas nos Projetos Integradores e no decorrer dos componentes curriculares, atividades de iniciação científica, publicações de artigos, apresentação de trabalhos em eventos científicos, publicação de trabalhos em anais de eventos, seja por meio de resumos, resumos expandidos ou trabalhos completos. Em termos institucionais, ressaltamos que o IFRS possui programas internos e externos de fomento à pesquisa que ofertam bolsas a projetos (selecionados por meio de editais públicos), nos quais os docentes da Instituição submetem seus projetos de pesquisa, de acordo com sua área de interesse e com sua atuação nos cursos e nos grupos de pesquisa. 
Com relação às atividades de extensão, elas abrangem, entre outros, cursos e programas de extensão, participação em eventos científicos, participação de comissões, Semanas Acadêmicas de Cursos, ação social e comunitária desenvolvidas no Campus ou mesmo aquelas que os discentes buscaram em outras instituições como participantes externos. As ações de extensão do Campus são fomentadas pela instituição, a partir das políticas implementadas pela Diretoria de Extensão, de modo a atender aos princípios que norteiam a constituição dos Institutos Federais, permitindo sua articulação com o Ensino e à Pesquisa e possibilitando uma permanente interação dialógica com os diversos segmentos da sociedade.

Ressalta-se ainda que, dentre outras atividades previstas, podem ser consideradas as atividades práticas articuladas entre os sistemas de ensino e instituições educativas, capazes de propiciar vivências nas diferentes áreas do campo educacional, assegurando aprofundamento e diversificação de estudos, experiências e utilização de recursos pedagógicos; as atividades desenvolvidas durante o período de mobilidade estudantil ou intercâmbio; bem como as atividades de comunicação e expressão visando à aquisição e à apropriação de recursos de linguagem capazes de comunicar, interpretar a realidade estudada e criar conexões com a vida social.

Ao final do curso, os discentes sistematizam os estudos mediante a produção de uma monografia que caracteriza o Trabalho de Conclusão de Curso (TCC), a qual é resultante de uma pesquisa realizada individualmente e que é socializada e avaliada por banca especializada, conforme previsto na resolução própria do Campus.

O Estágio é realizado em duas modalidades, a saber, obrigatório ou nãoobrigatório. O primeiro integra a matriz curricular do Curso de Licenciatura, sendo regulamentado internamente e pela legislação vigente no país. É constituído por quatro etapas: a primeira a partir do $6^{\circ}$ semestre, com duração de 100 horas, em Ciências da Natureza nos anos finais do ensino fundamental; a segunda e a terceira a partir do $7^{\circ}$ semestre, em Biologia e Química para o ensino médio, com duração de 100 horas cada; a quarta, no nono semestre, com duração de 100 horas em Ciências da Natureza no Ensino Médio. Já o estágio não-obrigatório é desenvolvido por interesse do discente e não constitui componente curricular do Curso de 
Licenciatura (ainda que possa ser aproveitado como horas de Estudos Integradores - a pedido do discente e aprovado pelo Coordenador de Curso).

As metodologias de ensino adotadas no decorrer do Curso de Licenciatura em Ciências da Natureza: Biologia e Química incluem estratégias pedagógicas diversas visando promover a articulação entre teoria e prática. Cabe destacar que, de acordo com o disposto nas Diretrizes Nacionais para a Formação (2015):

a escolha das metodologias de ensino requer compreender que a educação engloba processos formativos para além do ensino em sala de aula, ou seja, abrange os processos pedagógicos entre os profissionais e estudantes articulados nas áreas de conhecimento específico e/ou interdisciplinar e pedagógico, nas políticas, na gestão, nos fundamentos e nas teorias sociais e pedagógicas para a formação ampla e cidadã e para o aprendizado nos diferentes níveis, etapas e modalidades de Educação Básica. (BRASIL, 2015, p. 43)

Diante disso, as estratégias adotadas visam contemplar os objetivos propostos no Curso bem como nas Diretrizes Curriculares Nacionais para a Formação Inicial e Continuada dos Profissionais do Magistério da Educação Básica, compreendendo a docência enquanto:

ação educativa e como processo pedagógico intencional e metódico, envolvendo conhecimentos específicos, interdisciplinares e pedagógicos, conceitos, princípios e objetivos da formação que se desenvolvem na socialização e construção de conhecimentos, no diálogo constante entre diferentes visões de mundo. (BRASIL, 2015, p. 21)

Tais ações incluem aulas expositivas dialogadas, estudos individuais e coletivos, práticas de ensino, monitorias, estágios curriculares, ações de pesquisas e extensão, participação em eventos, entre outras atividades acadêmico-científicas visando aprimorar e consolidar as experiências dos acadêmicos no decorrer de seus percursos formativos.

Diante do exposto, destaca-se ainda a necessidade da garantia da autonomia docente na definição das metodologias de ensino, as quais devem pautar-se numa perspectiva dialógica e contextualizada da educação, que se efetiva de modo sistemático e sustentável. 


\section{Considerações finais: desafios e perspectivas para a implementação do Projeto Pedagógico na atual conjuntura}

Os Institutos Federais, dadas as características concebidas desde sua criação, se constituem em profícuos espaços de fazeres que integram o ensino, a pesquisa e a extensão. Essas oportunidades são privilegiadas tanto pela verticalização do ensino, quanto pela diversidade de oportunidades que o corpo docente possui ao participar das ações nessas três áreas que constituem o tripé das ações da instituição. A premissa institucional da verticalização do ensino se constitui como importante eixo articulador da indissociabilidade entre ensino, pesquisa e extensão, uma vez que os docentes atuantes no curso de licenciatura trabalham tanto na educação básica como nos cursos de pós-graduação.

Entre os desafios postos na atual conjuntura, um dos principais será a adoção de estratégias que possibilitem a continuidade dos estudos por parte dos estudantes. Tal afirmativa se justifica pelo fato de que, à medida que aumentam os cortes orçamentários, em particular, na área de assistência estudantil, também há um crescimento no número de evasões. Aliado a isso, temos também a necessidade de maiores investimentos na área de políticas inclusivas, em especial, para o atendimento qualificado de licenciandos que ingressam na cota para deficientes. Este é um dos aspectos que ainda demanda maior atenção por parte das atuais políticas públicas voltadas à formação docente, ou seja, garantir condições mínimas para que a inclusão ocorra. Isso implica, dentre outras coisas, recursos para adequação das estruturas existentes (tais como bancadas de laboratório, equipamentos acessíveis, fomento a pesquisas na área de tecnologias assistivas, entre outros). A restrição orçamentária também repercute na falta de recursos para o investimento em materiais e manutenção de estruturas fundamentais tais como os laboratórios e aquisição de acervo bibliográfico.

Apesar de tais dificuldades, o Curso tem se destacado pelo entrelaçamento do ensino, pesquisa e extensão, cujas ações estão em consonância com os estudos recentes. Entre tais autores, Gonçalves (2015) destaca que a formação docente deve necessariamente envolver uma discussão e apresentar caminhos para a flexibilização curricular visando: 
- assumir a produção do conhecimento como princípio metodológico e pedagógico;

- considerar o diálogo com desafios e demandas de distintos segmentos da sociedade, postos - em especial, mas não somente - para aquela área ou profissão, em um processo de reflexão sobre o próprio currículo e a formação ali desenvolvida, e os conhecimentos necessários para a atuação profissional e cidadã;

- fomentar e oportunizar diálogos interdisciplinares que permitam uma reflexão mais abrangente e profunda da própria formação, dos conhecimentos nela envolvidos e da atuação profissional futura;

- estabelecer diálogos com distintos saberes que perpassam a sociedade, que podem contribuir para a reflexão e articulação dos conhecimentos postos no próprio processo formativo, e para a produção de novos conhecimentos, entre outros. (GONÇALVES, 2015, p. 1251)

Logo, com base em tais premissas, o projeto pedagógico do Curso de Licenciatura busca fomentar espaços para o desenvolvimento dos objetivos acima elencados. Busca ainda o atendimento de demandas da comunidade interna e externa, bem como a qualificação e o aprimoramento constante de tais processos formativos.

\section{Referências}

BRASIL. Lei n. 9.394, de 20 de dezembro de 1996. Diário Oficial da União, Brasília, 23 de dezembro de 1996.

BRASIL. Lei no. 11.892, de 29 de dezembro de 2008. Diário Oficial da União, Brasília, 30 de dezembro de 2008.

BRASIL. Ministério da Educação. Resolução CNE/CP no 2, de 01 de julho de 2015. Diário Oficial da União, Brasília, 2 de julho de 2015.

DELORS, J. D. Educação: um tesouro a descobrir. São Paulo: Cortez, 1998. $281 \mathrm{p}$.

FREIRE, P. Pedagogia da autonomia: saberes necessários à prática educativa. Rio de Janeiro: Paz e Terra, 1996. Disponível em http://www.apeoesp.org.br/sistema/ck/files/4-

\%20Freire_P_\%20Pedagogia\%20da\%20autonomia.pdf acessado em 03/06/2017.

GADOTTI, Moacyr. Boniteza de um sonho: ensinar-e-aprender com sentido. Novo Hamburgo, RS. Editora Feevale, 2003. Disponível em http://www.ebooksbrasil.org/adobeebook/boniteza.pdf acessado em 05/06/2017. 
GOMES, N. L. Indagações sobre currículo: diversidade e currículo. Brasília: Ministério da Educação, Secretaria de Educação Básica, 2007.

GONÇALVES, N. G. Indissociabilidade entre Ensino, Pesquisa e Extensão: um princípio necessário. In: Revista Perspectiva: Florianópolis, v. 33, n.3, p. 1229 - 1256, set./dez. 2015. Disponível em: < https://periodicos.ufsc.br/index.php/perspectiva/issue/view/2325/showToc> Acesso em 6 jun. 2017.

INSTITUTO FEDERAL DE EDUCAÇÃO CIÊNCIA E TECNOLOGIA DO RIO GRANDE DO SUL. Projeto Pedagógico do Curso de Licenciatura em Ciências da Natureza: Biologia e Química. Porto Alegre, 2016.

MOREIRA, A.F. Conhecimento, currículo e ensino: questões e perspectivas. In. Em Aberto. Brasília, ano 12, n.58, abr./jun. 1993. Disponível em http://www.rbep.inep.gov.br/index.php/emaberto/article/view/1890/1861 acessado em 05/06/2017. 